\section{Políticas e produção científica: diálogos entre trabalho e educação na saúde}

Scientific policies and production:

dialogues between work and education in health

\section{Tânia Celeste Matos Nunes ${ }^{2}$}

O estudo realizado sobre o "estado da arte" do trabalho e da educação na saúde, na perspectiva da produção científica da área cumpre um papel mobilizador e instigante, apontando tendências e vazios que são matérias de diálogo com outros elementos dos contextos relacionados ao período escolhido pelos autores. E esse é o caminho que pretendo seguir nesse debate.

O estudo é também relevante, pela importância da matéria de recursos humanos/trabalho e educação, que é parte essencial das políticas e práticas do setor saúde. Há uma convergência com temas filiados ao processo de constituição do Sistema Único de Saúde, o que confere a essa produção um expressivo componente de engajamento no debate das políticas públicas do setor.

A vertente da profissionalização está muito presente nas matérias relacionadas às categorias de Formação e Capacitação de Trabalhadores, mas integra também os trabalhos agrupados na categoria de Mercado de Trabalho, Política e Administração de Recursos Humanos, com a Educação Permanente em Saúde, temática que introduz inovações no campo da educação na saúde nos anos mais recentes. Nos estudos relacionados à categoria dos profissionais de saúde, também se expressa a forte característica de engajamento, notadamente nas subcategorias de processo de trabalho e saúde do trabalhador.

Vale mencionar que nos anos de 1980 trava-se um debate importante sobre a municipalização do Sistema de Saúde brasileiro, mas é na década de 1990 que se materializa essa implantação, trazendo a necessidade de novos olhares aos processos de trabalho, à gestão do trabalho e à formação dos trabalhadores vinculados aos municípios brasileiros, fenômeno que pode ter influenciado a elevação do padrão de produção, que se dá a partir de 1996, com maior ênfase a partir do ano de 2006.

Como decorrência das diretrizes que passaram a orientar a Reforma do Estado nos anos de 1990, os temas relacionados à gestão do trabalho, principalmente aqueles relacionados às terceirizações, produzem mudanças na área em relação à compreensão anterior de vínculos e de remuneração de trabalhadores, tanto no setor público quanto no privado. Esse fenômeno provocou uma renova- ção das categorias analíticas até então adotadas pela área de trabalho e educação, sendo recorrente, entre os pesquisadores, a necessidade de realizar estudos sobre a precarização, a desregulamentação das relações de trabalho, a captação e a gestão dos trabalhadores para o setor, entre outras subcategorias mencionadas pelos autores.

Ainda no campo do Trabalho, vale mencionar que, nesse período, inicia-se no âmbito da Comissão Interinstitucional de Recursos Humanos do Conselho Nacional de Saúde-CIRH um movimento de formulação de políticas, com um padrão alternativo de referência técnica e política, em contraposição ao que se implantava naquele momento no âmbito do Estado (contexto de Reforma do Estado com ajuste fiscal). O movimento dos trabalhadores de saúde se organiza nesse espaço, e formula a NOB-RH, de forma participativa e articulada com instituições e outros grupos organizados do setor saúde, nascendo desse esforço, um novo padrão de organização das políticas da área, revelando temas instigantes para análise dos grupos de pesquisa, e que serviu de base para a formulação de políticas públicas inovadoras no período pós 2003.

O expressivo aumento da produção científica da área a partir de 2005, revelado pelo artigo apresentado, pode estar refletindo as demandas por reflexão e análise que passaram a ser significativas no debate da NOB-RH, abrindo a possibilidade do surgimento de estudos de questionamentos aos formatos das relações de trabalho adotados no contexto de reforma do Estado dos anos de 1990. De outro modo, a necessidade de ampliação da visibilidade do novo padrão de referência construído pelo debate da NOB-RH, pode ser considerado um fator de mobilização de estudos relacionados a esse objetivo. Nesse particular, parece provável que a categoria da terceirização tenha produzido estudos que aprofundam a sua associação com políticas restritivas de Estado e com a globalização. Em outra dimensão, os estudos de novas perspectivas para as políticas de trabalho podem ter produzido estímulos para os estudos de temas acolhedores à participação dos trabalhadores nas políticas do setor (mesas de negociação) e mobilizadores de uma relação de trabalho amparada nos princípios de legalidade envolvendo o Estado e a classe trabalhadora (desprecarização).

No que se refere à categoria de formação/capacitação dos trabalhadores e em uma subcatego-

${ }^{2}$ Departamento de Escola de Governo em Saúde, Escola
Nacional de Saúde Pública, Fundação Oswaldo Cruz. tcnunes@globo.com 
ria da política e administração de RHS (Política de Educação Permanente) é possível perceber a importância dos estudos analisados, compreendendo a sua contribuição à organização do setor saúde e mais especificamente ao SUS.

Como analisado pelos autores, esse tema da educação na saúde está na origem da criação dessa área, com as contribuições de Donnangelo, Schreiber, Sérgio Arouca, Juan Cesar Garcia e Jairnilson Paim, seguidos de outros pensadores que se engajaram nessa produção ao longo do tempo, com estudos diversificados, incorporação de novas temáticas e novas teorias e contornando uma tendência que tem sido renovada, ao longo do período analisado pelo artigo em debate.

$\mathrm{Na}$ educação dos profissionais de saúde também se evidencia a relação entre a produção científica e as políticas e práticas construídas na esteira das propostas governamentais. Esse movimento de diálogo permanente entre os dois mundos favoreceu a construção de uma identidade para a área de educação na saúde e seus produtos passaram a se constituir como referência, quando se pensa na evolução da profissionalização do setor.

Os dados apresentados pelos autores configuram um conjunto de temas que se entrecruzam na produção científica e na constituição de políticas e práticas da área, desde a I Conferência de Recursos Humanos para a Saúde, em 1986, quando se aponta para a inadequação da formação dos profissionais de saúde. Já nos anos de 1990 evidencia-se o tema do ensino médico, das residências e da formação dos profissionais de saúde, da educação continuada dos profissionais do setor, seguido dos esforços de aprofundamento da Integração Docente Assistencial, com contribuições das Redes IDA e UNI e posteriormente da Rede Unida. A integração ensino x serviço (IDA) atravessa os ciclos de organização da formação em saúde no Brasil desde os anos de 1980, perpassando os Programas de Medicina Comunitária ${ }^{1}$, o Projeto Larga Escala de Formação de Nível Médio², o PROFAE 3 , o PROFAPS $^{4}$, o PROSAÚDE ${ }^{5}$, PET-SAÚDE e a PNEPS ${ }^{6}$ entre outras iniciativas de formação com aproximação entre a formação e os Serviços de Saúde. Não é sem razão que os documentos revisados pelos autores do artigo em debate destacam a sinergia que se configura na conformação desses projetos, pelo conjunto de artigos analisados, acolhendo no entanto, as ponderações de Marandola et al. quando analisam a Educação Permanente em trabalhos da Rede Unida e referem a necessidade de buscar elementos conceituais que contribuam para a melhoria do entendimento dessa proposta, ainda confundida com a educação continuada.
Vale destacar a relação entre o aporte de recursos governamentais para a pesquisa, principalmente a partir de 2005, que coincide com uma significativa tendência de crescimento da produção na área de trabalho e educação, apresentada pelos autores, sobre a evolução do período considerado (Gráfico de 2012).

Em consonância com as conclusões dos autores do artigo em debate, parece pertinente manter a tendência de ampliação da produção de pesquisas na área, mas principalmente, buscar superar, na seleção de objetos, o caráter militante intrínseco a essa área. A maturidade dos programas de pós-graduação nas diferentes regiões do Brasil conseguida a partir da segunda metade da década de 1990, a expansão dos mestrados profissionais, os mestrados acadêmicos e os doutorados nos últimos anos, são fatores que agregam possibilidades à manutenção e ao aperfeiçoamento do padrão de produção da área. Outro elemento concreto é a existência de fontes de financiamento na estrutura do Ministério da Saúde pelas Secretarias de Gestão do Trabalho e Educação na Saúde e Ciência e Tecnologia em Saúde.

Finalmente, a existência de um debate permanente sobre a produção dessa área, que tem sido a tônica do GT de Trabalho e Educação da Abrasco, e a existência de Redes de Formação com agendas ativas de produção de conhecimento no nível médio e na pós graduação, podem ser elementos impulsionadores de uma produção teórica consoante com o desenvolvimento da área e com o reconhecimento social que ela já adquiriu.

\section{Referências}

1. Paim JS. A Formação de Recursos Humanos em Saúde Coletiva. In: Paim JS. Saúde crise e reformas. Salvador: UFBa-PROED; 1986. (Coleção Monográfica Série Reitor Miguel Calmon)

2. Santos I. Entrevista. Rev. Trabalho, Educação e Saúde 2004; 2(1):203-207.

3. Sório R. Educação Profissional em Saúde no Brasil: a proposta das Escolas Técnicas do Sistema Único de Saúde. Revista Formação 2002; 2(5):46-58.

4. Brasil. Ministério da Saúde (MS). Portaria GM/MS $n^{\circ} 1626$ de 24 de junho de 2010. Define recursos financeiros do MS para o Programa de Formação de Nível Médio para a Saúde (PROFAPS). Diário Oficial da União 2010; 25 jun.

5. Brasil. Ministério da Saúde (MS). MS-PROSAUDE: Programa Nacional de Reorientação da Formação Profissional em Saúde. MS-MEC. Brasília: Editora do Ministério da Saúde; 2005.

6. Ferraz JS, Vendrusco C, Kleba M, Prado M, Reibinitz K. Ações Estruturantes Interministeriais para Reorientação da Atenção Básica em Saúde: convergência entre educação e humanização. O Mundo da Saúde 2012; 36(3):482-493. 